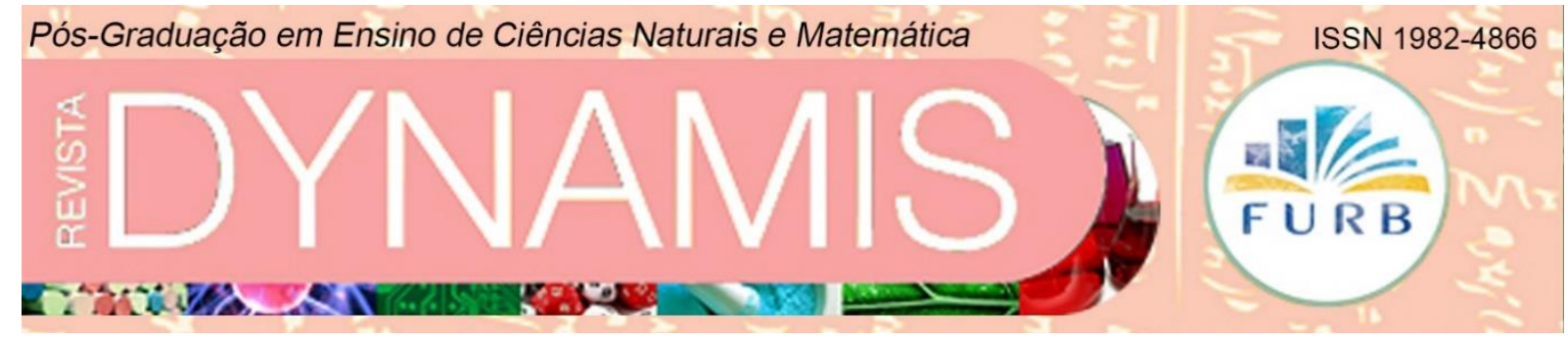

\title{
HISTÓRIA DA MATEMÁTICA NA EDUCAÇÃO PROFISSIONAL: UMA ANÁLISE DE LIVROS-TEXTO DE ELETRÔNICA DIGITAL E DE CIRCUITOS DE CORRENTE CONTÍNUA
}

History of Mathematics in vocational education: an analysis of textbooks of digital electronics and direct current circuits

Lauro Chagas e Sá

Instituto Federal do Espirito Santo

proflaurosa@gmail.com

Fabricio Bortolini de Sá

Instituto Federal do Espírito Santo

fabricio.sa@ifes.edu.br

Giuseppe Togneri Polonini

Instituto Federal do Espírito Santo

tognerepoloninig@gmail.com

Joice de Souza Soares

Instituto Federal do Espírito Santo

joicess29@gmail.com 


\title{
Resumo
}

Este trabalho apresenta uma pesquisa relacionada à História da Matemática que analisou como os livros-texto ${ }^{1}$ de Eletrônica Digital e de Circuitos de Corrente Contínua abordam elementos históricos relacionados à Álgebra de Boole e às Leis de Kirchhoff, respectivamente. As obras analisadas pertencem ao acervo da biblioteca da nossa instituição e são utilizadas como referências nas disciplinas do Curso Técnico em Automação Industrial Integrado ao Ensino Médio. No que tange ao aspecto metodológico, desenvolvemos uma pesquisa bibliográfica, selecionando para análise os livros mais acessados pelos estudantes em cada disciplina. Verificamos que a maioria dos exemplares analisados não apresenta adequadamente a história. Como acreditamos que a formação profissional deve compreender conhecimentos técnicos e científicos em sua historicidade, concluímos que seria importante investigar as possibilidades da História da Ciência para o ensino da técnica.

Palavras-chave: História da Matemática. Educação Profissional. Livro-Texto. Álgebra de Boole. Leis de Kirchoff.

\begin{abstract}
This paper presents a research related to the History of Mathematics that analyzed how the textbooks of Digital Electronics and Direct Current Circuits present historical elements related to Boolean Algebra and Kirchhoff Laws, respectively. The analyzed books belong to the collection of the library of our institution and they are used as references in the disciplines of the Technical Course in Industrial Automation Integrated to High School. Regarding the methodological aspect, we developed a bibliographical research, selecting for analysis the books most accessed by the students in each discipline. We verified that most of the analyzed material do not adequately present the history. As we believe that vocational education should understand technical and scientific knowledge in its historicity, we conclude that it would be important to investigate the possibilities of the History of Science for teaching the technique.
\end{abstract}

Keywords: History of Mathematics. Vocational education. Textbook. Boolean algebra. Laws of Kirchoff.

${ }^{1}$ Livros-textos são obras adotadas nas escolas como texto básico para determinada disciplina, segundo o Dicionário Michaelis. Optamos por não utilizar a terminologia "livros didáticos", por desenvolvermos uma pesquisa em obras que tratam de conteúdos do núcleo profissional e que, eventualmente, não possuem a estrutura de um livro didático. 


\title{
1 INTRODUÇÃO
}

A pesquisa com foco na análise e no desenvolvimento de livros didáticos tem ganhado destaque no cenário internacional da pesquisa em Educação Matemática. Em território nacional, exemplificamos investigações dessa natureza com os trabalhos de Vianna (1995), Bianchi (2006) e Pereira (2016). Esse último concluiu recentemente que as menções à História da Matemática ainda não estão sendo apresentadas conforme orienta a literatura da área de Educação Matemática. Entretanto, a pesquisa aponta uma melhoria, se comparado com as análises de Vianna (1995) e Bianchi (2006).

Em outra experiência, Civiero et al (2016) também desenvolveram um estudo em relação à História da Ciência em livros didáticos. Os pesquisadores selecionaram sete coleções de matemática e coleções coleções de física para analisar, no volume 1 de cada coleção, a intersecção dos tópicos de História e Filosofia da Ciência para os conteúdos de funções, nos livros de matemática, e fundamentos da dinâmica, nos livros de física. Adotando uma categorização das menções em ilustração, o grupo concluiu que a História e a Filosofia da Ciência são apresentadas de forma fragmentada, ilustrativa e acrítica no contexto geral das obras de física. Nas obras de matemática, Civiero et al (2016) verificaram que é mais ostensiva a ausência da história e da filosofia:

\begin{abstract}
Praticamente não existem referências à história da matemática, tampouco sobre o pensamento filosófico. É muito comum a cópia de ilustrações e do fragmento histórico utilizado sem o devido contexto nos LD [livros didáticos] de matemática e de física. Alguns LD utilizam as relações dos conceitos com questões contemporâneas, sem buscar a historicidade do seu desenvolvimento e sem alguma relação com o pensamento filosófico, demostrando uma perspectiva de descontinuidade, acriticidade e linearidade (CIVIERO et al, 2016, p. 14).
\end{abstract}

Estabelecendo um diálogo entre as pesquisas de Pereira (2016) e Civiero et al (2016), é possível perceber que, apesar da existência do Plano Nacional do Livro Didático (PNLD), muitos livros ainda não atendem às orientações curriculares no que diz respeito à presença da História da Ciência. Essas reflexões motivaram-nos a direcionar nossos olhares para os livrostextos da Educação Profissional, que não possuem uma política pública de análise e que são adotados por professores bacharéis sem formação pedagógica, em sua maioria ${ }^{2}$. Nesse caso, se compararmos com o quadro docente da formação geral, muito mais professores do núcleo profissional utilizam os livros-texto como único material pedagógico e de formação. Ou seja, sem a ausência de uma abordagem adequada no material didático, as práticas pedagógicas na Educação Profissional reduzem-se apenas a uma aplicação do conhecimento, sem explorar o desenvolvimento dos conceitos.

Com base no que Paulo Freire escreve sobre a educação, é possível afirmar que, para ele, a educação profissional deve ser entendida como um processo de formação humana: "a formação técnico-científica de que precisamos é muito mais do que puro treinamento ou adestramento para uso de procedimentos tecnológicos" (FREIRE, 2000, p. 101 apud MANFREDI, 2010, p. 140). Para Manfredi (2010), é possível afirmar que as ideias de Paulo

\footnotetext{
${ }^{2}$ A Resolução nº. 6/2012 do Ministério da Educação, que define Diretrizes Curriculares Nacionais para a Educação Profissional Técnica de Nível Médio, traz, em seu Art. 40, que os professores graduados, não licenciados, deverão, até o ano de 2020, participar de um curso de pós-graduação lato sensu, de caráter pedagógico, ou ter reconhecidos seus saberes profissionais em processos destinados à formação pedagógica.
} 
Freire se aproximam mais da concepção que faz da formação para o trabalho um processo mais amplo e complexo da formação humana. Nesse sentido, a formação profissional, assim como a formação básica de nível médio, também deve compreender conhecimentos técnicos e científicos, em sua historicidade e com a função social e política. Por esse motivo, iniciamos uma série de pesquisas relacionando a História da Matemática e a formação de estudantes da Educação Profissional de nível médio.

Considerando o cenário descrito, esta produção apresenta resultados de dois projetos de pesquisa $^{3}$, desenvolvidos no contexto do Grupo de Pesquisa Educação Matemática e Educação Profissional - EMEP. Diante disso, o objetivo é analisar se é e como é abordada a história da Álgebra Booleana em livros-texto de Sistemas Digitais e a história das Leis de Kirchoff em obras de Circuito de Corrente Contínua. Adotamos este recorte, porque as disciplinas citadas pertencem à matriz curricular do Curso Técnico de Automação Industrial Integrado ao Ensino Médio, ao qual os pesquisadores estão vinculados.

Antes de estudarmos como é feita a abordagem da história nos livros-texto, apresentaremos uma contextualização histórica dos conteúdos propostos, os referenciais teóricos que orientaram nosso estudo e os aspectos metodológicos deste trabalho.

\section{UMA INTRODUÇÃO À HISTÓRIA DOS CONTEÚDOS PROPOSTOS}

\subsection{DA ÁLGEBRA DE BOOLE À ELETRÔNICA DIGITAL}

O processo de industrialização na Europa, ocorrido no final do século XVIII e início do século XIX, modificou o estilo de vida de milhões de pessoas. Essas grandes transformações também influenciaram na matemática produzida no período, pois o novo modelo de produção incentivou os pesquisadores a buscarem a praticidade do conhecimento, com a finalidade de aprimorar os processos industriais (MONTALVÃO et al., 1998 apud SOUSA, 2008). Assim, a divisão do trabalho, caracterizada pela especialização das tarefas no ambiente da fábrica, acarretou em uma divisão e especialização da matemática, que já não era apenas uma, mas sim diferentes campos de estudo - que juntos formavam uma ciência ainda maior.

Decorrente da especialização da matemática, a lógica foi um dos campos que recebeu grande atenção de pesquisadores. Foi no século XIX que se começou a busca da relação entre a lógica e a matemática: um momento da quebra dos padrões aristotélicos por meio da criação conhecida como Lógica Matemática. Essa lógica iniciou-se com a publicação de The Mathematical Analysis of Logic e Formal Logic, escritos por Augustus de Morgan (1806-1871) e por George Boole (1815-1864), respectivamente. Apesar de publicarem suas obras sobre lógica quase simultaneamente, os matemáticos seguiram caminhos diferentes. Em comum, apenas a busca por expandir a lógica aristotélica, ainda vigente no período, por meio de sua formalização.

Uma das realizações mais importantes de De Morgan foi a preparação do caminho para o nascimento da lógica simbólica (ou matemática). Já Boole definiu as teorias matemáticas da lógica e da probabilidade e, ao mesmo tempo, construiu a lógica formal. Sua obra $A n$

\footnotetext{
${ }^{3}$ Os projetos "Das álgebras de Boole à eletrônica digital: recriando cenários da história da matemática" e "Grafos e redes: uma abordagem histórico-investigativa para a Educação Profissional" são desenvolvidos no Programa Institucional de Bolsas de Iniciação Científica Junior - PIBIC-Jr, com financiamento do Instituto Federal do Espirito Santo.
} 
investigation into the Laws of Thought iniciou a álgebra da lógica, conhecida como Álgebra Booleana, muito aplicada na computação. Pelas suas contribuições no desenvolvimento da Matemática, Boole recebeu vários títulos de universidades importantes como a Oxford.

Os métodos algébricos introduzidos por Boole atraíram a atenção de muitos matemáticos e sofreram diversas mudanças com o passar do tempo. Ainda assim, a álgebra booleana ficou um período sem aplicação direta, até que Claude Elwood Shannon (1916-2001), pesquisador do Massachusetts Institute of Technology, com formação em matemática e engenharia elétrica, visualizou uma aplicação para esta lógica. Em A Symbolic Analysis of Relay and Switching Circuits, Shannon (1938) utilizou a Álgebra de Boole para solucionar problemas de circuitos de telefonia com relés, introduzindo na área tecnológica o campo da Eletrônica Digital. A tese de Shannon foi considerada brilhante pela comunidade acadêmica, sendo aplicada quase que de imediato nos sistemas chaveados de telefone automático. Assim, esse processo, que começou com os relés de Shannon, transformou-se nos transistores e finalmente nos microchips, que possibilitam uma vasta variedade de aplicações e mudaram nosso mundo novamente.

\subsection{GRAFOS, CIRCUITOS ELÉTRICOS E AS LEIS DE KIRCHOFF}

No século XVIII, cidadãos prussianos ${ }^{4}$ de Königsberg costumavam passar suas tardes a caminhar em torno da sua localidade, constituída por quatro áreas de terra separadas pelo Rio Pregel, sobre o qual havia sete pontes. Então, os cidadãos fixaram um problema: caminhar ao redor da cidade, cruzando cada uma das sete pontes apenas uma vez e, se possível, retornar ao seu ponto de partida. Em 1730, o prefeito de uma cidade próxima a Königsberg passou a se corresponder com Leonhard Euler para discutir o problema das sete pontes, o que motivou a criação da Teoria de Grafos (SÁ, 2014).

Depois de passar por um século de pouco desenvolvimento, a Teoria dos Grafos apresenta-se na segunda metade do século XIX, impulsionada pelos problemas de aplicação em diversas áreas. Boaventura Netto (2006) cita a utilização de modelos de grafos no estudo de circuitos elétricos, em 1847, por Gustav Robert Kirchhoff (1824-1887), e dez anos mais tarde, na enumeração dos isômeros dos hidrocarbonetos alifáticos saturados, por Arthur Cayley (1821-1895).

Gustav Kirchhoff foi um físico que nasceu na cidade de Königsberg, quase um século depois que Euler resolveu o Problema das Sete Pontes. Sua família pertencia à comunidade intelectual e, por isso, Kirchhoff foi criado para servir à Prússia, tornando-se, no auge de sua carreira, professor universitário. Nessa época, acreditava-se que pessoas com certas habilidades tinham muito o que contribuir com o Estado (O'CONNOR; ROBERTSON, 2002).

Kirchhoff matriculou-se na universidade para o estudo da matemática no verão de 1842. Enquanto participava de um seminário de física-matemática entre 1843 e 1846, o prussiano começou a estudar circuitos elétricos, buscando aplicações matemáticas para a resolução de problemas dessa natureza. Na Universidade Albertus de Königsberg, Kirchhoff foi aluno dos matemáticos Carl Gustav Jakob Jacobi (1804-1851) e Friedrich Julius Richelot (1808-1875) e do físico Franz Ernst Neumann (1798-1895), sendo este último seu principal incentivador.

\footnotetext{
${ }^{4}$ A Prússia foi uma região histórica da Europa, que fazia fronteira com a costa sudeste do mar Báltico. Após séculos de conquistas, uniões e separações, deu origem à Alemanha, em 1871, tornando-se parte desse outro país.
} 
Enquanto estudava com Neumann, Kirchhoff fez sua primeira contribuição nos estudos sobre correntes elétricas, associando à Teoria de Grafos aos Circuitos Elétricos. Seus estudos, que posteriormente formalizaram-se nas leis que recebem nome do cientista, estabeleceram que a soma algébrica das correntes em qualquer nó de um circuito é sempre nula, ou seja, um nó não acumula carga ( $1^{\mathrm{a}}$ Lei de Kirchooff) e que a soma algébrica da diferença de potencial elétrico ou tensão elétrica em qualquer malha de um circuito é sempre nula ( $2^{\mathrm{a}}$ Lei de Kirchooff). Portanto, ao utilizar conceitos de grafos para resolução de problemas, Kirchhoff acabou por contribuir para o desenvolvimento teórico e prático de diversos campos da ciência.

Foi somente no ano de 1847 que Kirchhoff publicou o seu trabalho. Nesse ano, ele formou-se em Königsberg e se mudou para Berlim, em um momento particularmente difícil, quando as tensões lá eram altas devido à Revolução de Março e às más condições na Confederação Germânica. O desemprego e as falhas de colheita haviam levado ao descontentamento e às perturbações; sentimentos republicanos e socialistas mostravam que a monarquia estava em apuros. Kirchhoff, no entanto, estava em uma posição privilegiada e não foi afetado por eventos ao seu redor, enquanto ele avançava com sua carreira (O'CONNOR; ROBERTSON, 2002).

\title{
3 REFERENCIAIS TEÓRICOS
}

Uma reflexão sobre a utilização da História na Educação Matemática nos conduz a uma escolha teórica. Os pontos de vista são variados e dependem da visão que cada professor/ pesquisador tem da História e dos valores que estão presentes nessa, enquanto metodologia de ensino. Nesta pesquisa, preocupamo-nos em analisar se os livros-textos utilizados em disciplinas do núcleo profissional abordam os contextos históricos dos conteúdos, pois acreditamos que a História da Matemática é uma rica fonte de experiências e produções humanas, que oportuniza um diálogo entre práticas atuais e fontes históricas, conforme previsto nas Orientações Curriculares para o Ensino Médio:

\begin{abstract}
A utilização da História da Matemática em sala de aula também pode ser vista como um elemento importante no processo de atribuição de significados aos conceitos matemáticos. É importante, porém, que esse recurso não fique limitado à descrição de fatos ocorridos no passado ou à apresentação de biografias de matemáticos famosos. A recuperação do processo histórico de construção do conhecimento pode se tornar um importante elemento de contextualização dos objetos e de conhecimento que vão entrar na relação didática (BRASIL, 2006, p. 86).
\end{abstract}

Mendes (2016) ressalta sua percepção diante de seus anos de experiência na formação de professores de Matemática, visão importante para este trabalho, pois nos possibilita um embasamento teórico da real importância da história no ensino. Segundo o pesquisador, o ensino da matemática

[...] pode ser mais enriquecido quando associado a aspectos históricos que envolvem a produção de conhecimento matemático no tempo, no espaço e nos contextos socioculturais em que esse conhecimento foi produzido e utilizado. [...] o uso didático da investigação histórica tem muita contribuição para o ensino da matemática, no sentido de possibilitar aos estudantes um exercício de verificação dos processos e produtos estabelecidos na construção das matemáticas abordadas pela escola, com 
relação à sua presença em diversas situações referentes à construção de nossa realidade sociocultural ao longo da história (MENDES, 2016, p. 2).

No contexto da educação profissional, em especial, Ramos (2005) defende que é a partir do conhecimento na sua forma mais contemporânea que se pode compreender a realidade e a própria ciência na sua historicidade. Assim, segundo a autora, os processos de trabalho e as tecnologias correspondem a momentos do desenvolvimento das forças materiais de produção e podem ser tomados, em sala de aula, como ponto de partida histórico e dialético para o processo pedagógico:

\footnotetext{
Histórico porque o trabalho pedagógico fecundo ocupa-se em evidenciar, juntamente com os conceitos, as razões, os problemas, as necessidades e as dúvidas que constituem o contexto de produção de um conhecimento. A apreensão de conhecimento na sua forma mais elaborada permite compreender os fundamentos prévios que levaram ao estágio atual de compreensão do fenômeno estudado. Dialético porque a razão de estudar um processo de produção não está na sua estrutura normal e procedimental aparente, mas na tentativa de captar os conceitos que os fundamentam e as relações que os constituem (RAMOS, 2005, p. 120).
}

Em nossa concepção, os conceitos científicos seriam os "pontos de partida" que deveriam se reverter em conteúdos de ensino, sistematizados em diferentes áreas de conhecimento e em diversas disciplinas. A partir do exposto por Ramos (2005), percebemos, então, que "conhecimentos gerais e conhecimentos profissionais se distinguem metodologicamente e em suas finalidades situadas historicamente; porém, epistemologicamente, esses conteúdos formam uma unidade" (RAMOS, 2005, p. 120). Dessa forma, ao tratar de tópicos comuns às disciplinas básicas e profissionais, a partir da História da Matemática, acreditamos reconstituir a totalidade do conhecimento científico a partir da relação entre as partes organizadas em disciplinas. Também nos aproximaríamos de um movimento de interdisciplinaridade - necessário principalmente na Educação Profissional (GONÇALVES; PIRES, 2014), uma vez que trataríamos de uma temática transversal, viabilizada, neste caso, pela História da Matemática.

Em uma categorização referente ao uso de História da Matemática, Dynnikov e Sad (2007) apresentam três opções para o emprego de fontes históricas em sala de aula: de modo factual, de modo processual e como fonte de significado. No primeiro caso, a História da Matemática é utilizada para dar mais veracidade, por meio de nomes, imagens e registros. Assim, essa metodologia se apresenta de modo ilustrativo e estático, na qual a única incumbência do professor é escolher o material e preparar a exposição. A segunda forma, mais dinâmica, percebe as fontes históricas como instrumentos que auxiliam no ensino de Matemática, pois permitem que o aluno conheça o processo realizado por um Matemático para a resolução de um problema. Nesse caso, ainda não há uma transposição da história para o contexto escolar, e o papel do professor é mediar e auxiliar nos registros. No terceiro modo de se utilizar de História em sala de aula, o papel das fontes históricas (primárias e secundárias) é produzir significados em meio às próprias experiências dos alunos, proporcionando, principalmente, uma ampliação da maneira com que eles entendem e lidam com a Matemática. Nesse caso, o professor precisa intensificar o dinamismo e os ecos produzidos pela voz de autores nos alunos. 


\section{ASPECTOS METODOLÓGICOS}

Esta pesquisa, por ser desenvolvida com base em material já publicado, pode ser classificada como pesquisa bibliográfica (FIORENTINI; LORENZATO, 2007). Para sua execução, foram utilizadas as etapas recomendadas por Gil (2002, p. 59), que são: escolha do tema; levantamento bibliográfico preliminar; formulação do problema; elaboração do plano provisório de assunto; busca das fontes; leitura do material; fichamento; organização lógica do assunto; redação do relatório com os resultados obtidos.

O tema escolhido foi História da Matemática na Educação Profissional. Nosso objetivo foi, portanto, o de analisar como a história da Álgebra de Boole e das Leis de Kirchhoff é abordada nos livros-texto de Eletrônica Digital e de Circuitos de Corrente Contínua. Em seguida, como desdobramento, objetivamos classificar os livros-texto, a partir dos conteúdos propostos, de acordo com nosso referencial teórico: os que realizam uma transposição da história para o contexto escolar; os que apresentam o processo realizado por um Matemático; os que apenas citam nomes, datas ou locais (modo ilustrativo); e os que não se apropriam da história e são, portanto, exclusivamente técnicos (DYNNIKOV; SAD, 2007).

Listamos todos os livros de Eletrônica Digital e de Circuitos de Corrente Contínua presentes no acervo da biblioteca do IFES campus Linhares, onde é ofertado o Curso Técnico em Automação Industrial Integrado ao Ensino Médio. Localizamos 45 exemplares de 8 títulos diferentes de Eletrônica Digital e 14 exemplares de 8 títulos diferentes de Corrente Contínua. Em seguida, com apoio dos servidores da biblioteca, verificamos a quantidade de empréstimos desses livros ao longo do ano de 2016, até a data da coleta de dados. Todas as informações básicas referentes ao livros estão sintetizadas nas tabelas 1 e 2 .

Tabela 1 - Livros de Eletrônica Digital disponíveis na biblioteca institucional, com quantidade de empréstimos

\begin{tabular}{|c|c|c|c|}
\hline Título do livro & Autor(es) & $\begin{array}{l}\text { Quantidade } \\
\text { absoluta de } \\
\text { empréstimos }\end{array}$ & $\begin{array}{l}\text { Quantidade } \\
\text { relativa de } \\
\text { empréstimos }\end{array}$ \\
\hline Elementos da Eletrônica Digital & $\begin{array}{c}\text { Ivan V. Idoeta } \\
\text { Francisco G. Capuano }\end{array}$ & 114 & $60,64 \%$ \\
\hline Circuitos Digitais & $\begin{array}{l}\text { Antônio Carlos de Lourenço } \\
\text { Eduardo Cesar Alves Cruz } \\
\text { Sabrina Rodero Ferreira } \\
\text { Salomão Choueri Júnior }\end{array}$ & 16 & $8,51 \%$ \\
\hline Eletrônica Digital & $\begin{array}{l}\text { James W. Bignell } \\
\text { Robert Donovan }\end{array}$ & 12 & $6,38 \%$ \\
\hline Eletrônica digital moderna e VHDL & Volnei A. Pedroni & 12 & $6,38 \%$ \\
\hline $\begin{array}{l}\text { Sistemas Digitais: projeto, otimização e } \\
\text { HDLS }\end{array}$ & Frank Vahid & 12 & $6,38 \%$ \\
\hline $\begin{array}{l}\text { Eletrônica Digital: Teoria e } \\
\text { Laboratório }\end{array}$ & $\begin{array}{l}\text { Paulo Alves Garcia } \\
\text { José Sidnei Colombo Martini }\end{array}$ & 9 & $4,79 \%$ \\
\hline $\begin{array}{l}\text { Fundamentos da eletrônica digital: } \\
\text { sistemas combinacionais }\end{array}$ & Roger Tokheim & 8 & $4,26 \%$ \\
\hline $\begin{array}{l}\text { Sistemas Digitais: Princípios e } \\
\text { aplicações }\end{array}$ & $\begin{array}{l}\text { Ronald J. Tocci } \\
\text { Neal S. Widmer } \\
\text { Gregory L. Moss }\end{array}$ & 5 & $2,66 \%$ \\
\hline Total & & 188 & $100 \%$ \\
\hline
\end{tabular}

Fonte: Elaborado pelos autores, 2016. 
Tabela 2 - Livros de Circuitos de Corrente Contínua disponíveis na biblioteca institucional, com quantidade de empréstimos.

\begin{tabular}{|c|c|c|c|}
\hline Título & Autor & $\begin{array}{l}\text { Quantidade } \\
\text { absoluta de } \\
\text { empréstimos }\end{array}$ & $\begin{array}{l}\text { Quantidade } \\
\text { relativa de } \\
\text { empréstimos }\end{array}$ \\
\hline $\begin{array}{l}\text { Circuitos elétricos: Corrente Contínua e } \\
\text { Corrente alternada }\end{array}$ & Otávio Markus & 33 & $32,35 \%$ \\
\hline Circuitos elétricos & James William Nilsson & 28 & $27,46 \%$ \\
\hline Circuitos e medidas elétricas & Belmiro Wolski & 15 & $14,7 \%$ \\
\hline Circuitos elétricos & $\begin{array}{l}\text { Yaro Burian Júnior } \\
\text { Ana Cristina Lyra }\end{array}$ & 7 & $6,86 \%$ \\
\hline Fundamentos de circuitos elétricos & Charles K. Alexander & 7 & $6,86 \%$ \\
\hline Análise de circuitos de engenharia & William Hart Heyt & 6 & $5,89 \%$ \\
\hline Análise de circuitos elétricos & Paulo Antônio Mariotto & 4 & $3,92 \%$ \\
\hline Introdução aos circuitos elétricos & Richard C. Dorf & 2 & $1,96 \%$ \\
\hline Total & & 102 & $100 \%$ \\
\hline
\end{tabular}

Fonte: Elaborado pelos autores, 2016.

Adotamos a quantidade de empréstimos como critério de seleção, pois é de nosso interesse saber se os livros-texto mais consultados pelos estudantes contemplam a história da matemática de alguma maneira. Assim, com base nas tabelas apresentadas, formulamos a lista de livros para análise, incluindo obras até que a frequência acumulada se aproximasse de $3 / 4$ do total. No caso da tabela 1, havia três livros com mesma quantidade de empréstimos e, por isso, decidimos selecionar as cinco obras mais utilizadas em Eletrônica Digital, correspondendo a $88,3 \%$ do total. Pela tabela 2, selecionamos os três livros de Circuitos de Corrente Contínua mais acessados, que correspondem juntos a 74,51\% dos empréstimos realizados.

\section{RESULTADOS E DISCUSSÃO}

Uma vez apresentado o processo histórico e a importância deste estudo na disciplina, passaremos a verificar se os livros utilizados abordam esta dimensão. Apresentaremos inicialmente os cinco livros de Eletrônica Digital e, em seguida, os três livros de Circuitos de Corrente Contínua.

Em Circuitos Digitais (LOURENÇO et al, 2007), há um capítulo dedicado a Álgebra Booleana e Circuitos Combinacionais. Antes de apresentar o conteúdo técnico, o livro aborda, em três páginas, a história da lógica: cita a Grécia antiga, com Sócrates, Platão e Aristóteles, e traz a lógica formal desenvolvida por George Boole. Em seguida, apresenta Claude Shannon e quando e como a álgebra booleana foi utilizada na prática.

Ao apresentar a Grécia Antiga, Lourenço et al (2007) retomaram a questão política envolvendo os governantes e sofistas e falaram sobre os debates públicos. Ao tratar do julgamento e condenação à morte de Sócrates pelos políticos, os autores incluíram o seguinte trecho: "caros leitores, qualquer semelhança com mundo atual é mera coincidência!" (LOUREÇO et al, 2007, p. 35). Com isso, percebemos que esse livro-texto faz com que os alunos produzam significados em meio às suas próprias experiências (DYNNIKOV; SAD, 
2007) e compreendam o conhecimento científico, em sua historicidade, com a função social e política (FREIRE, 2010). Dessa forma, podemos associar esse livro-texto ao nível mais elevado do uso da História da Matemática.

\section{Figura 1 - Início do capítulo 3: Álgebra Booleana e Circuitos Combinacionais.}

\begin{tabular}{|c|c|}
\hline $\begin{array}{cl}\text { Capítulo Álgebra } \\
\text { Booleana } \\
\text { e Circuitos } \\
\text { Combinacionais }\end{array}$ & \begin{tabular}{|l|} 
3.1 Uma Breve História da Lógica \\
3.2 Fundamentos \\
3.3 Portas Lógicas \\
3.4 Circuitos Combinacionais \\
3.5 Simplificaçäo de Expressöes Booleanas \\
- Exercícios Propostos \\
- Projetos
\end{tabular} \\
\hline $\begin{array}{l}\text { Para falarmos em álgebra b } \\
\text { Grécia antiga, alguns séculos antes de } \\
\text { pouco da história da Lógica que é a basec } \\
\text { mas também para entendermos melhor }\end{array}$ & $\begin{array}{l}\text { Oooleana é importante voltarmos à } \\
\text { Cristo, não só para conhecermos um } \\
\text { da Eletrônica Digital e da Informática, } \\
\text { r seus conceitos. }\end{array}$ \\
\hline
\end{tabular}

Fonte: Lourenço et al (2007. p. 35)

Na obra Elementos da Eletrônica Digital, Idoeta e Capuano (2012) apresentam uma rápida explicação da história, citando nomes dos pesquisadores, títulos de trabalhos, datas e locais. Abordam de uma maneira bem resumida como se encadearam os processos históricos até que fosse possível implementar a álgebra de Boole na prática, mas não se aprofundam nesses processos. Em seguida partem para os estudos técnicos das portas lógicas, explicam como cada uma delas funciona. No capítulo seguinte, os autores abordam a álgebra de Boole, apresentam seus postulados e as propriedades desenvolvidas por George Boole, assim como apresentam teoremas de De Morgan. Apesar da abordagem sintética, acreditamos que o livro-texto permite que o aluno conheça o processo realizado para a resolução de um problema e, assim, atribuímos a essa obra o nível intermediário, na classificação de Dynnikov e Sad (2007).

\section{Figura 2 - Introdução à Álgebra Booleana}

\begin{tabular}{|l|}
\hline 2.1 Introdução \\
Em 1854, o matemático inglês George Boole (1815-1864), através da obra \\
intitulada An Investigation of the Laws of Thought, apresentou um sistema \\
matemático de análise lógica conhecido como álgebra de Boole. \\
No início da "era da eletrônica", todos os problemas eram resolvidos por \\
sistemas analógicos, também conhecidos por sistemas lineares. \\
Apenas em 1938, o engenheiro americano Claude Elwood Shannon uti- \\
lizou as teorias da álgebra de Boole para a solução de problemas de circuitos de \\
telefonia com relés, tendo publicado um trabalho denominado Symbolic Analysis \\
of Relay and Switching, praticamente introduzindo na área tecnológica o campo \\
da eletrônica digital. \\
Esse ramo da eletrônica emprega em seus sistemas um pequeno grupo de \\
circuitos básicos padronizados conhecidos como portas lógicas. \\
Através da utilização conveniente destas portas, podemos "implementar" \\
todas as expressões geradas pela álgebra de Boole, que constituem a base dos \\
projetos dos sistemas já referidos. \\
Este capítulo trata apenas dos blocos básicos, deixando para os capítulos \\
posteriores o estudo de outros blocos e sistemas derivados.
\end{tabular}

Fonte: Idoeta; Capuano (2012. p. 60) 
O livro Eletrônica Digital Moderna e VHDL (PEDRONI, 2010) apresenta primeiramente as portas lógicas, explicando seu funcionamento. Em seguida, apresenta alguns circuitos combinacionais, tais como somador, flip-flop, registrador de deslocamento, contadores, entre outros. O capítulo seguinte aborda a álgebra booleana. O autor cita George Boole como fundador dessa álgebra, e logo em seguida passa a explicá-la de forma técnica, sem um estudo histórico a respeito do assunto. Assim, esse livro se enquadra na categoria factual, em que a história é usada apenas para dar mais veracidade (DYNNIKOV; SAD, 2007).

\section{Figura 3 - Álgebra Booleana}

\section{1 ÁLGEBRA BOOLEANA}

A análise formal de circuitos digitais é baseada na álgebra booleana, cujos fundamentos foram propostos por G. Boole [Boole54] na década de 1850. Contém um conjunto de regras matemáticas que comandam um sistema de dois valores (binário) representado por zeros e uns. Tais regras são discutidas neste capítulo, acompanhadas de vários exemplos. Para representar valores de bits ou de vetores de bits, sempre que adequado empregaremos novamente a sintaxe VHDL que consiste em um par de aspas simples para bits isolados ou um par de aspas duplas para vetores de bits.

Fonte: Pedroni (2010. p. 91)

O livro Sistemas Digitais: projeto, otimização e HDLs (VAHID, 2008), possui um capítulo que aborda as portas lógicas e a lógica booleana. Nesse tópico, ele apresenta algumas definições de álgebra geral e da álgebra booleana para que, em seguida, parta para o estudo das portas lógicas. O livro cita que a álgebra booleana recebe esse nome em homenagem ao matemático britânico e até menciona que, em sua origem, a álgebra não era utilizada para construir circuitos lógicos. No entanto, as informações, assim como no livro-texto anterior, também são apresentadas de modo ilustrativo e estático (DYNNIKOV; SAD, 2007).

\section{Figura 4 - A álgebra booleana e sua relação com circuitos digitais.}

\section{A álgebra booleana e sua relação com os circuitos digitais}

Felizmente, na tarefa de projeto, as portas lógicas booleanas ajudam-nos, permitindo representar os blocos construtivos dos circuitos digitais de uma forma com a qual se pode trabalhar com muito mais facilidade do que com chaves. A lógica booleana foi desenvolvida em meados do século 19 pelo matemático George Boole, não para construir circuitos digitais (os quais não eram nem mesmo um vislumbre aos olhos de qualquer pessoa), mas como um esquema para usar os métodos algébricos na formalização da lógica e raciocínio humanos.

Fonte: Vahid (2008, p. 54)

Com um capítulo dedicado ao estudo das portas lógicas e outro à Álgebra de Boole, o livro Eletrônica Digital (BIGNELL; DONOVAN, 2010) apresenta o funcionamento das portas e no capítulo seguinte explica a Álgebra de Boole de forma exclusivamente técnica, sem apresentar fatores históricos, ou citando nomes locais e datas. 
Figura 5 - Capítulos 2 e 3: Portas Lógicas, Formas de Onda e Álgebra Booleana.

\section{(9) 2.1 PORTAS}

Portas são circuitos utilizados para combinar níveis lógicos digitais (1s e 0s) de formas específicas. Um sistema denominado álgebra booleana é utilizado para expressar a saída em termos das entradas. As portas básicas são inversor, OR, AND, NAND e NOR.

\subsection{TEOREMAS BOOLERNOS}

Examinaremos dois métodos para desenvolver o diagrama lógico necessário para determinada tabela-verdade. O primeiro método requer álgebra booleana e os teoremas de DeMorgan para

Fonte: Bignell; Donovan (2010. p. 42; 102)

No caso da disciplina de Circuitos de Corrente Contínua, os livros deixam muito a desejar em relação ao uso da História da Matemática. O livro que possuir maior nível de incorporação da história ainda está no modo factual (DYNNIKOV; SAD, 2007). Em Circuitos elétricos (NILSSON; RIEDEL, 2009), os autores informam apenas que o nome das Leis de Kirchhoff se deve a Gustav Kirchhoff, o primeiro a enunciá-las em um artigo publicado em 1848 , conforme imagem a seguir.

Figura 6 - Leis de Kirchoff.

\subsection{Leis de Kirchhoff}

Diz-se que um circuito está resolvido quando a tensão nos terminais de cada elemento e a corrente correspondente foram determinadas. A lei de Ohm é uma equaçăo importante para derivar essas soluçôes. Contudo, essa lei pode nåo ser suficiente para dar uma solução completa. Como veremos ao tentar resolver o circuito da lanterna do Exem. plo 2.4, precisamos usar duas relações algébricas mais importantes, conhecidas como leis de Kirchhoff, para resolver a maioria dos circuitos.

\begin{abstract}
A interconexão de elementos de circuito impóe limitaçốes à relaçăo entre as tensốes e correntes nos terminais. Essas limitą̧ôes são denominadas leis de Kirchhoff, nome que se deve a Gustav Kirchhoff, o primeiro a enunciá-las em um artigo publicado $\mathrm{em} \mathrm{1848.} \mathrm{As} \mathrm{duas} \mathrm{leis} \mathrm{que} \mathrm{determinam} \mathrm{as} \mathrm{li-}$ mitą̧ôes em linguagem matemática são conhecidas como a lei das correntes de Kirchhoff e a lei das tensôes de Kirchhoff.
\end{abstract}

Fonte: Nilsson; Riedel (2009. p. 23-24)

Nos demais livros-texto analisados, Circuitos elétricos: Corrente Contínua e Corrente Alternada (MARKUS, 2008) e Circuitos e Medidas Elétricas (WOLSKI, 2010), não há nenhum fragmento da história. As obras expõem o conteúdo de forma objetiva e concisa, sem apresentar nenhum elemento historiográfico, o que contribui para uma "visão aproblemática e ahistórica, que transmite conhecimentos já elaborados como fatos assumidos sem mostrar os problemas que geraram sua construção" (VALDÉS, 2006, p. 19). 
Figura 7 - Leis de Kirchoff.

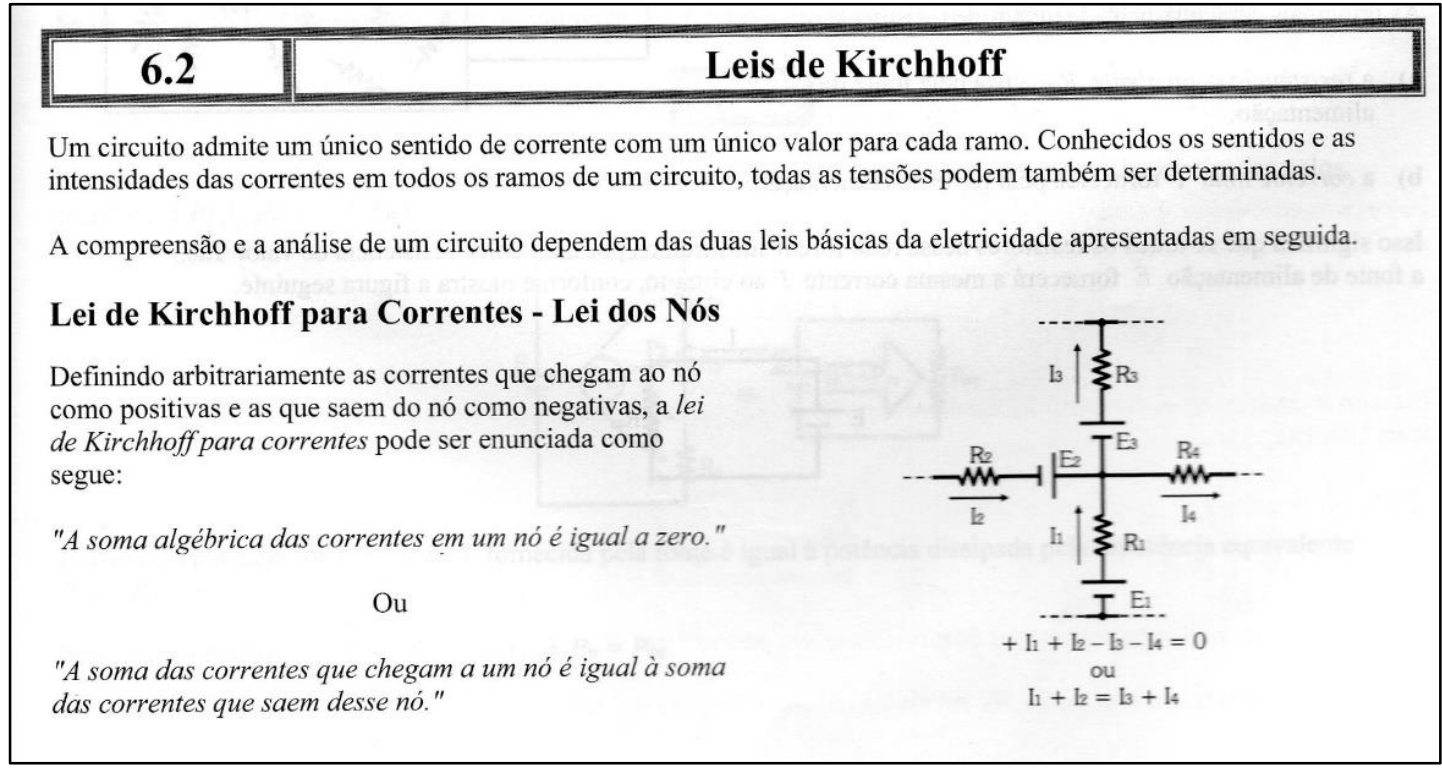

Fonte: Markus (2008. p. 43)

Figura 8 - Leis de Kirchoff.

Existem resistências que alteram seus valores à medida que uma tensão diferente é aplicada, resultando em correntes que não se relacionam linearmente com a tensão. Na realidade, a maioria das resistências, na prática, assume este comportamento em maior ou menor grau. Essas resistências são ditas não ôhmicas.

\section{Lei de Kirchhoff}

O somatório das correntes que chegam em um nó é igual ao somatório das correntes que saem desse mesmo nó.

$$
\sum I_{\text {chegam }}=\sum I_{\text {sam }}
$$

\section{Lei de Kirchhoff}

Em uma malha qualquer de uma rede elétrica, o somatório das forças eletromotrizes é igual ao somatório das quedas de tensão.

$$
\sum_{\text {fom }}=\sum_{\text {quedas }}
$$

Fonte: Wolski (2010. p. 9)

Em síntese, verificamos que os livros de Eletrônica Digital apresentam mais informações históricas que os de Circuitos de Corrente Contínua. No caso da primeira disciplina, a obra que possui ampla maioria de empréstimos está no nível intermediário em relação ao uso da história e o livro-tex to que a sucede neste ranking está no nível mais adequado para apresentação da história. Já no caso da segunda disciplina, apenas um título explora a história de Kirchhoff e, ainda assim, de modo factual. 


\section{ALGUMAS CONSIDERAÇÕES}

A partir desta pesquisa bibliográfica, verificamos que, de modo geral, são raros os livros-texto que possuem uma abordagem adequada da história do conteúdo profissional a ser estudado. Dos cinco livros mais utilizados em Eletrônica Digital, um apresenta abordagem histórica em nível adequado, um pode ser classificado como nível intermediário, dois citam nomes, datas, locais e apenas um é exclusivamente técnico. Ao analisar os três livros didáticos mais usados na disciplina de Circuitos de Corrente Contínua, observamos que aparece pouco da história do conteúdo, sendo apresentados apenas nomes e datas.

Como resultado, verificamos que a maioria dos exemplares analisados não apresenta adequadamente a história; quando citam, tratam apenas de fragmentos ao introduzir os conteúdos. Como acreditamos que a formação profissional deve compreender conhecimentos técnicos e científicos em sua historicidade, concluímos que seria importante investigar as possibilidades da História da Ciência para o ensino da técnica. Por fim, o que desejamos, juntamente a outros pesquisadores da área de Educação, é a construção de uma perspectiva crítica e reflexiva do conhecimento da ciência e da tecnologia (CIVIERO et al, 2016). Nesse sentido, os livros-texto precisam ser percebidos como elementos importantes para o empoderamento dos educandos frente aos desafios atuais da Ciência e Tecnologia.

\section{Referências}

BIANCHI, Maria Isabel Zanutto. Uma reflexão sobre a presença da história da matemática nos livros didáticos. Dissertação de Mestrado, Programa de Pós-Graduação em Educação Matemática. ICGE/UNESP, Rio Claro, SP: 2006. Disponível em:

$<$ https://repositorio.unesp.br/bitstream/handle/11449/91102/bianchi_miz_me_rcla.pdf?sequen ce=1>. Acesso em: 22 abr. 2017.

BIGNELL, James W.; DONOVAN, Robert. Eletrônica Digital. São Paulo: Cengage Learning, 2010.

BOAVENTURA NETTO, Paulo Osvaldo. Grafos: Teoria, Modelos e Algoritmos. 4. ed. São Paulo: E. Blücher, 2006.

BOOLE, George. The Laws of thought. Toronto: Thoemmes Press, 1958. . The mathematical analysis of logic. Toronto: Thoemmes Press, 1998.

BRASIL. Secretaria de Educação Básica. Orientações curriculares para o Ensino Médio: Ciências da natureza, matemática e suas tecnologias. Brasília: MEC/SEF, 2006.

CIVIERO, Paula Andrea Grawieski. et al. Uma análise dos livros didáticos de matemática e física: intersecções de temas de História e Filosofia da Ciência. In: Seminário Nacional de História da Ciência e da Tecnologia, 15º. Anais... Florianópolis: SBHC, 2016.

DE MORGAN, Augustus. Formal Logic. Hawaii: University Press of the Pacific, 2003.

DYNNIKOV, Circe Mary Silva da Silva; SAD, Lígia Arantes. Uma abordagem pedagógica para o uso de fontes originais em História da Matemática. Guarapuava: SBHMat, 2007. 
História da matemática na educação profissional: uma análise de livros-texto de eletrônica digital e de circuitos de corrente contínua

FIORENTINI, Dario; LORENZATO, Sergio. Investigação em Educação Matemática: percursos teóricos e metodológicos. Coleção formação de professores. 2.ed. Campinas, SP: Autores Associados, 2007.

FREIRE, Paulo. Pedagogia da indignação: cartas pedagógicas e outros escritos. São Paulo: Editora Unesp, 2000.

GIL, Antônio Carlos. Como elaborar projetos de pesquisa. 4. ed. São Paulo: Atlas, 2002. . Métodos e Técnicas de Pesquisa Social. 6. ed. São Paulo: Atlas, 2008.

GONÇALVES, Harryson Júnio Lessa; PIRES, Célia Maria Carolino. Educação matemática na educação profissional de nível médio: análise sobre possibilidades de abordagens interdisciplinares. Bolema, abr. 2014, vol.28, n. 48, p. 230-254.

IDOETA, Ivan V.; CAPUANO, Francisco G. Elementos da Eletrônica Digital. 41. ed. São Paulo: Érica, 2012.

LOURENÇO, Antônio Carlos de et al. Circuitos Digitais. 9. ed. São Paulo: Érica, 2007.

MANFREDI, Silvia Maria. Educação profissional. In: STRECK, Danilo R.; REDIN, Euclides; ZITKOSKI, Jaime José. Dicionário Paulo Freire. 2. ed., ver. amp. 1 reimp. Belo Horizonte: Autêntica Editora, 2010.

MARKUS, Otávio. Circuitos Elétricos: Corrente Contínua e Corrente Alternada: Teoria e Exercícios. 8. ed. São Paulo: Érica, 2008.

MENDES, Iran Abreu. A dinâmica operatória da investigação histórica nas aulas de matemática. In: Encontro Nacional de Educação Matemática, XII. Anais...São Paulo - SP: SBEM, 2016.

NILSSON, James William; RIEDEL, Susan A. Circuitos Elétricos. 8. ed. São Paulo: Pearson Prentice Hall, 2009.

O'CONNOR, J. J.; ROBERTSON, E. F. Gustav Robert Kirchhoff. 2002. Disponível em: <http://www-history.mcs.st-and.ac.uk/Biographies/Kirchhoff.html>. Acesso em: 22 nov. 2016.

PEDRONI, Vonei A. Eletrônica Digital Moderna e VHDL. Rio de Janeiro: Elselvier, 2010.

PEREIRA, Elisângela Miranda. A História da Matemática nos livros didáticos de Matemática do Ensino Médio: conteúdos e abordagens. Dissertação (Mestrado em Ensino de Ciências) Universidade Federal de Itajubá, 2016. Disponível em:

$<$ https://repositorio.unifei.edu.br/xmlui/bitstream/handle/123456789/476/dissertacao_pereira_ 2016.pdf? sequence $=1 \&$ is Allowed=y>. Acesso em: 22 abr. 2017.

RAMOS, Marise. Possibilidades e desafios na organização do currículo integrado. In: FRIGOTTO, Gaudêncio; CIAVATTA, Maria; RAMOS, Marise (orgs). Ensino Médio Integrado: concepção e contradições. São Paulo: Cortez, 2005.

SÁ, Lauro Chagas e. História da Teoria dos Grafos e algumas contribuições no Ensino Médio. Trabalho de Conclusão de Curso (Licenciatura em Matemática) - Instituto Federal do Espírito Santo, Vitória - ES, 2014. Disponível em:

<https://biblioteca2.ifes.edu.br/vinculos/00000E/00000EBF.pdf>. Acesso em: 9 jun. 2016.

SHANNON, Claude Elwood. A Symbolic Analysis of Relay and Switching Circuits.

Transactions of the American Institute of Electrical Engineers, v. 57, 1938.

SOUSA, G. C. D. Um estudo sobre as origens da Lógica Matemática. Tese (Doutorado em Educação) - Centro de Ciências Sociais Aplicadas, Universidade Federal do Rio Grande do 
Norte. Natal, RN. 2008. Disponível em:

<http://repositorio.ufrn.br:8080/jspui/handle/123456789/14129?mode=full >. Acesso em: 08 set. 2016.

VAHID, Frank. Sistemas Digitais: projeto, otimização e HDLS. Porto Alegre: Bookman, 2008. $558 \mathrm{p}$.

VALDÉS, Juan E. Nápoles. A história como elemento unificador na educação matemática. In: MENDES, Iran Abreu; FOSSA, John A.; VALDÉS, Juan E. Nápoles. A História como um agente de cognição na Educação Matemática. Porto Alegre: Editora Sulina, 2006, p. 15-78.

VIANNA, Carlos Roberto. Matemática e História: algumas relações e implicações pedagógicas. Dissertação de Mestrado, Faculdade de Educação, USP, 1995.

WOLSKI, Belmiro. Circuitos e Medidas elétricas. Curitiba: Base Editorial, 2010. 